\title{
Embodied learning in the classroom: Effects on primary school children's attention and foreign language vocabulary learning
}

\author{
Mirko Schmidt ${ }^{\mathrm{a}, *}$, Valentin Benzing ${ }^{\mathrm{a}}$, Amie Wallman-Jones ${ }^{\mathrm{a}}$, Myrto-Foteini Mavilidi ${ }^{\mathrm{b}}$, \\ David Revalds Lubans ${ }^{\mathrm{b}}$, Fred Paas, ${ }^{\mathrm{c}, \mathrm{d}}$ \\ a Institute of Sport Science, University of Bern, Bremgartenstrasse 145, 3012 Bern, Switzerland \\ ${ }^{\mathrm{b}}$ Priority Research Centre for Physical Activity and Nutrition, School of Education, University of Newcastle, Newcastle, Australia \\ ${ }^{\mathrm{c}}$ School of Education/Early Start Research Institute, University of Wollongong, Wollongong, New South Wales, 2522, Australia \\ ${ }^{\mathrm{d}}$ Department of Psychology, Education, and Child Studies, Erasmus University Rotterdam, 3062, PA, Rotterdam, the Netherlands
}

\section{A R T I C L E I N F O}

\section{Keywords:}

Exercise

Integrated physical activity

Intervention

Embodied cognition

Acute physical activity

Chronic physical activity

\begin{abstract}
A B S T R A C T
Objectives: The aim of the present study was to investigate the effects of specifically designed physical activities on primary school children's foreign language vocabulary learning and attentional performance. Design: A total of 104 children aged between 8 and 10 years were assigned to either (a) an embodied learning condition consisting of task-relevant physical activities, (b) a physical activity condition involving task-irrelevant physical activities, or (c) a control condition consisting of a sedentary teaching style. Within a 2-week teaching program, consisting of four learning sessions, children had to learn 20 foreign language words.

Method: Children were tested on their memory performance (cued recall test) after completion of the program and on their focused attention (d2-R test of attention) immediately after one learning session.

Results: Linear mixed model analyses revealed both the embodied learning $(d=1.12)$ and the physical activity condition $(d=0.51)$ as being more effective in teaching children new words than the control condition. Children's focused attention, however, did not differ between the three conditions.

Conclusions: The results are discussed in the light of embodied cognition and cognitive load theory. Implications for the inclusion of specific physical activities during the school day are proposed.
\end{abstract}

\section{Introduction}

The central importance of movement for healthy child development is widely recognized in politics, science, and education. Yet despite the growing evidence supporting the benefits of regular physical activity for children's physical (Poitras et al., 2016) and mental health (Lubans et al., 2016), it appears that most school-aged children are not sufficiently active (Tremblay et al., 2014). The secular trend indicating a decline in children's physical activity levels (Hallal et al., 2012) is not only alarming in terms of their physical health, but also in terms of their cognitive development. This concern comes from knowing that motor and cognitive abilities are strongly interrelated, and together predict academic achievement in young people (Donnelly et al., 2016; Oberer, Gashaj, \& Roebers, 2018; Schmidt et al., 2017). Considering this, programs introducing more physical activity into schools, with the shared goal of promoting the amount of daily physical activity and the cognitive performance of all school-aged children, are often called for (Cox, Schofield, \& Kolt, 2010; Naylor \& McKay, 2009).

Besides enhancing physical activity levels (e.g. Kibbe et al., 2011; Riley, Lubans, Holmes, \& Morgan, 2016), classroom-based physical activity interventions seem to be effective at influencing academic-related outcomes (Erwin, Fedewa, Beighle, \& Ahn, 2012; Watson, Timperio, Brown, Best, \& Hesketh, 2017). Classroom-based physical activity can be distinguished into (1) physical activity breaks; consisting of short bouts of physical activity between the delivery of academic lessons and (2) integrated physical activity; incorporating physical activity during academic lessons (Webster, Russ, Vazou, Goh, \& Erwin, 2015). Interestingly, these two types of classroom-based physical activity have been studied by different disciplines, through applying different methodologies referring to diverse theories to measure various outcome variables (Mavilidi, Ruiter et al., 2018). Exercise and cognition research has predominantly referred to the physiological changes

\footnotetext{
* Corresponding author. Institute of Sport Science, University of Bern, Bremgartenstrasse 145, 3012 Bern, Switzerland.

E-mail addresses: mirko.schmidt@ispw.unibe.ch (M. Schmidt), valentin.benzing@ispw.unibe.ch (V. Benzing), amie.wallman-jones@ispw.unibe.ch (A. Wallman-Jones), myrto.mavilidi@newcastle.edu.au (M.-F. Mavilidi), david.lubans@newcastle.edu.au (D.R. Lubans), fredp@uow.edu.au, paas@essb.eur.nl (F. Paas).
} 
induced by single bouts of gross motor exercise as an explanation for the effects of physical activity on cognitive functioning (Etnier, Salazar, Landers, Petruzzello, \& Nowell, 1997; Khan \& Hillman, 2014; Lubans et al., 2016) and academic achievement (Donnelly et al., 2016). Contrastingly, embodied cognition research has mainly focused on psychological models in explaining the influences on cognitive processes and learning (e.g., Goldin-Meadow \& Beilock, 2010), discussing them in the context of subtle movements such as gestures, and more recently whole-body movements (e.g., Lindgren, Tscholl, Wang, \& Johnson, 2016).

\subsection{Physical activity breaks}

The effects of acute physical activity breaks have generally been researched by exercise scientists by targeting the main outcome variables of on- and off-task behaviour (Bartholomew et al., 2018; Howie, Beets, \& Pate, 2014; Ma, Le Mare, \& Gurd, 2014; Riley et al., 2016), executive functions (Benzing, Heinks, Eggenberger, \& Schmidt, 2016; Egger, Conzelmann, \& Schmidt, 2018; Howie, Schatz, \& Pate, 2015; Jäger, Schmidt, Conzelmann, \& Roebers, 2014; Jäger, Schmidt, Conzelmann, \& Roebers, 2015; Kubesch et al., 2009) and attention (Best, 2012; Budde et al., 2008; Gallotta et al., 2015, 2012; Hill et al., 2010; Palmer, Miller, \& Robinson, 2013; Schmidt, Benzing, \& Kamer, 2016; van den Berg et al., 2016). Since focused attention, defined as the voluntary act of trying to ignore certain stimuli while attending to others (Posner \& DiGirolamo, 1998), is an important prerequisite for learning (Steinmayr, Ziegler, \& Träuble, 2010) and a long-term predictor for children's academic achievement (Steele, Karmiloff-Smith, Cornish, \& Scerif, 2012), the effects of several ecologically valid physical activity interventions have been studied.

Researchers investigating focused attention have consistently reported positive effects when applying acute physical activity breaks ranging from 10 to $50 \mathrm{~min}$ in children and adolescents (Budde et al., 2008; Gallotta et al., 2015, 2012; Hill et al., 2010; Palmer et al., 2013; Schmidt et al., 2016; van den Berg et al., 2016). With respect to the content of these interventions, few attempts have been made to integrate cognitive learning tasks directly into the applied physical activity to facilitate the learning process of predefined academic concepts. Besides some notable exceptions (Pesce, Crova, Cereatti, Casella, \& Bellucci, 2009), studies have focused on acutely altered cognitive performance without considering the learning process itself (ÁlvarezBueno et al., 2017). However, considering that teachers report time constraints as being the most relevant barrier to implementing daily physical activity (Naylor et al., 2015), integrating physical activity into the learning of academic concepts may increase the added value of acute classroom-based physical activity.

When explaining the potential mechanisms underpinning the relationship between acute physical activity and cognition, the physiological responses provoked by acute (i.e., single bouts) physical activity include greater cerebral blood flow (Timinkul et al., 2008), increased release of various neurotrophins, e.g., brain-derived neurotrophic factor (Ferris, Williams, \& Shen, 2007; Winter et al., 2007), elevated glucocorticoid levels, e.g., cortisol (Blair, Granger, \& Peters Razza, 2005), and the release of catecholamines, e.g., epinephrine, norepinephrine, or dopamine (Winter et al., 2007). These neurophysiological changes are thought to lead to altered psychological states, such as increased arousal, making a larger pool of attentional resources available and therefore facilitating performance in cognitively effortful tasks (Audiffren, Tomporowski, \& Zagrodnik, 2009).

Recently, researchers started recognizing the importance of the qualitative characteristics of physical activity interventions (Pesce, 2012; Pesce \& Ben-Soussan, 2016), suggesting that various modalities of physical activity may not only differ in their intensity, duration, and frequency, but also, for example, in their coordinative and cognitive complexity (Vazou, Pesce, Lakes, \& Smiley-Oyen, 2016). The basic assumption of the cognitive stimulation hypothesis is that non-automated physical activities and coordinative demands activate the same brain regions that are used to control higher-order cognitive processes (Best, 2010; Pesce, 2012; Tomporowski, McCullick, Pendleton, \& Pesce, 2015). For the relation between acute physical activity and cognition, it is assumed that these cognitive demands during physical activity lead to better cognitive performance by pre-activating the same cognitive processes used in a subsequent cognitive task (Budde et al., 2008).

\subsection{Integrated physical activity}

Integrated physical activity has been researched by exercise scientists (Watson et al., 2017) and educational psychologists (Chandler \& Tricot, 2015), both differing in their theoretical and methodological approaches. Chronic physical activity studies generally focus on the interventions' effects on either the children's on-task behaviour (Bartholomew et al., 2011; Grieco, Jowers, \& Bartholomew, 2009; Mahar et al., 2006; Riley et al., 2016) or academic achievement (Beck et al., 2016; Donnelly et al., 2017, 2009; Mullender-Wijnsma et al., 2016), instead of how it improves the learning of a certain academic concept through the physical activity itself. Physical activities, such as spelling words by jumping in place for every letter during language learning (Mullender-Wijnsma et al., 2016) can be considered as nontask-relevant movements. Educational psychologists, however, are more interested in using task-relevant movements to find specific actions which can be translated into an academic concept.

Based on the theoretical framework of embodied cognition, action and perception are inextricably bound, where sensorimotor experiences of the external environment are grounded in cognitive processes (Barsalou, 2008; Glenberg, Witt, \& Metcalfe, 2013). In this sense, embodiment can be defined as the bodily states (i.e., arm movements and postures) arising from the interactions of the body with the semiotic world that are included in the cognitive processing. It is argued that embodying knowledge through motor actions contributes to the construction of higher-quality mental representations, facilitating recall, and enhancing memory and learning (Madan \& Singhal, 2012).

Complementary to the embodied cognition theory, recent advances in the cognitive load theory advocate the use of movements in learning complex tasks (Paas \& Sweller, 2012). Considering the limitations in duration and capacity of the human cognitive architecture, a fundamental distinction can be drawn between biological primary and biological secondary knowledge. Biological primary knowledge includes automatized, implicit knowledge that the human brain has specifically evolved to process with limited working memory resources. This information can be used with little effort, and sometimes even unconsciously (e.g., movements, basic communication skills in one or more languages, entrenched language). In contrast, biological secondary knowledge includes non-automatized information, based on culturally important knowledge that we have not been specifically evolved to acquire. This information requires explicit instruction, such as formal schooling and deliberate practice (e.g., higher language cognition, advanced foreign language, mathematics), as well as substantial amounts of mental effort and cognitive resources devoted during learning. Paas and Sweller (2012) have suggested that primary knowledge can be used to assist in the acquisition of biologically secondary knowledge. Supporting this suggestion, several studies have shown that the use of biologically primary knowledge, such as gestures, can reduce working memory load and facilitate learning of biologically secondary knowledge, such as mathematics (e.g., Cook, Yip, \& GoldinMeadow, 2012; Goldin-Meadow, Nusbaum, Kelly, \& Wagner, 2001; Goldin-Meadow \& Wagner, 2005).

In addition to the juxtaposed primary and secondary knowledge, cognitive load theory defines the total cognitive load on the learner's cognitive resources as the sum of the intrinsic and extraneous cognitive load (Sweller, 2010). Concomitantly, cognitive load is directly linked with the physical environments of the learning task (Choi, Van Merriënboer, \& Paas, 2014). Intrinsic cognitive load reflects the 
inherent complexity of the task, whereas extraneous cognitive load is related to the disruptive information from the physical characteristics of the learning tasks. In general, it is assumed that during learning of complex tasks, the available working memory resources are distributed between activities relevant to task performance (i.e., intrinsic load), and activities non-relevant to task performance (i.e., extraneous load).

Emerging empirical evidence supports the positive effects of gestures on learning mathematics (Cook, Mitchell, \& Goldin-Meadow, 2008; Goldin-Meadow \& Beilock, 2010), and whole-body movements in the form of physical activity on learning both mathematics (Riley et al., 2016; Shoval, 2011) and foreign language (Mavilidi, Okely, Chandler, Cliff, \& Paas, 2015; Toumpaniari, Loyens, Mavilidi, \& Paas, 2015). Focusing on the area of foreign language learning, two intervention studies in preschool children found that learning a second language was enhanced when children performed physical activity relevant to the meaning of the words to be learnt (i.e., integrated condition). These results were found when comparing the integrated condition to both a condition in which children were allowed only to gesture, and a condition representing the traditional sedentary instruction (Mavilidi et al., 2015; Toumpaniari et al., 2015). After four weeks of intervention, the authors of both studies attributed that the enhanced learning performance observed in the children of the integrated condition was due to the task-relevancy of the included physical activities.

\subsection{The present study}

To the best of our knowledge, an existing gap remains for primary school children in the domain of language learning. Moreover, all these studies have examined the learning performance after chronic interventions, without considering the acute impact on children's attentional performance. In terms of setting appropriate timetables and choosing the right time to administer physical activity during the school day, it might be of considerable importance to understand the effects to children's attention directly after a single session of embodied learning. Thus, the aim of the present study was to investigate the effects of specifically designed physical activities on primary school children's foreign language vocabulary learning and attentional performance. Three experimental conditions were set up to engage children in learning exotic animal names in French, either combined with meaningful physical activity (embodied learning), nonrelated physical activity (physical activity), or without physical activity (control) included. The hypotheses were: (1) Children of both physically active conditions will outperform those of the control condition in their learning outcomes. (2) Based on the literature on embodied cognition, it is further hypothesized that children of the embodied learning condition will show the greatest learning outcomes. (3) Based on the literature deriving from exercise and cognition research, children of both physically active conditions should show better focused attentional performance immediately after a learning session than those of the control condition.

\section{Material and methods}

\subsection{Subjects}

Participants of the study were 104 children $\left(M_{\text {age }}=9.04\right.$, $S D=0.70 ; 50$ girls) recruited from six elementary school classes in the region of Bern, Switzerland. These 3rd grade classes were randomly assigned to the experimental conditions, which resulted in two classes in the embodied learning condition consisting of task-related physical activities, two in the physical activity condition involving task-unrelated physical activities, and two in the control condition consisting of a sedentary teaching style.

Based on the reported learning effects (after two weeks) of an embodied learning intervention on children's cued recall performance in foreign language vocabulary learning (Mavilidi et al., 2015), an a priori power analysis (with 1 - beta error probability $=.80$; alpha error probability $=.05$; effect size $f=0.314$; number of groups $=3$ ) using G*Power 3 (Faul, Erdfelder, Lang, \& Buchner, 2007) was performed. An optimal sample size of $N=102$ was calculated.

There was some loss of data due to sick leave or incompletely filled questionnaires. The percentage of pupils with incomplete values ranged between $3.1 \%$ for the accelerometers and $5.8 \%$ for the $\mathrm{d} 2-\mathrm{R}$ test of attention. Since Little's Missing Completely at Random test (Little \& Rubin, 2002) was not significant, $\chi^{2}(231)=186.60, p=.986$, the missing values were imputed using the expectation-maximization (EM) algorithm. There were no significant differences between the three experimental conditions with respect to age, $F(2,101)=1.09$, $p=.340, \eta_{\mathrm{p}}{ }^{2}=0.021$, height, $F(2,101)=1.77, p=.175, \eta_{\mathrm{p}}{ }^{2}=0.034$, weight, $\quad F(2, \quad 101)=1.06, \quad p=.349, \quad \eta_{\mathrm{p}}{ }^{2}=0.021, \quad$ BMI, $\quad F(2$, $101)=0.84, p=.435, \eta_{\mathrm{p}}{ }^{2}=0.016$, gender distribution, $\chi^{2}(2)=1.32$, $p=.517$, Cramer's $V=0.113$, and socioeconomic status, $F(2$, 101) $=0.48, p=.622, \eta_{\mathrm{p}}{ }^{2}=0.009$.

The parents of the participating children signed an informed consent form approved by the Institutional Review Board prior to participating in the study. All children were asked before the first data collection session whether they wanted to participate, and informed that they could discontinue at any time during the study. All data were treated confidentially.

\subsection{General procedure}

The entire experiment consisted of three phases: pre-test, instruction, and a testing phase. A pre-test was conducted to assess children's prior knowledge by asking them to translate 38 exotic animal names from French to German.

In the instruction phase, the learning sessions included 20 animal names in French (words unknown to every child selected from the 38 words in the pre-test). The duration of the instruction phase was 2 weeks, consisting of one 10-min session 2 days per week. The learning sessions were conducted by a trained research student, accompanied by a video played on a big screen ensuring that all learning sessions were identical in terms of the sequencing of the words, numbers of repetitions and duration. All the words were presented both auditory and visually (picture of the animal as well as the word itself) to the children. After being presented, the children had to repeat each word three times alternating between French and their mother tongue. This process was identical for all experimental conditions. In the embodied learning condition, however, children had to enact the movements indicated by the animal name to be learned. For example, for the "short-tailed kangaroo", the children hopped like a kangaroo and positioned their angled arms in front of their torso. In the physical activity condition, children had to perform movements of the same intensity, but without being related to the animal name e.g. simply running on the spot. In the control condition, all animal names were repeated equally as often as in the former two conditions, but while being seated at the desk. ${ }^{1}$

In the testing phase, a wide range of additional data were gathered at different time points to avoid overloading children with extensive testing procedures: 1) Before the beginning of the first learning session, the $\mathrm{d} 2-\mathrm{R}$ test of attention (pre) was carried out. After the end of this first learning session, a questionnaire including background variables - age, gender, socioeconomic status (Boudreau \& Poulin, 2009) - was filled out, and children's height and weight were measured. 2) After the end of the second session, ratings of enjoyment and cognitive exertion were obtained. 3) During the third session, children were wearing accelerometers. Immediately after this third session, the $\mathrm{d} 2-\mathrm{R}$ test of attention (post) was conducted. 4) After the fourth session, the cued recall test was completed. All learning and testing sessions were conducted between 10.00 a.m. and 12.00 p.m.

\footnotetext{
${ }^{1} \mathrm{~A}$ list of the animal names and the respective videos can be obtained from the corresponding author.
} 


\subsection{Manipulation check and control variables}

Physical activity during the learning session was objectively measured by using Light Move 3 accelerometers (movisens GmbH, Karlsruhe, Germany). The Light Move 3 is a three-axial acceleration sensor with a measurement range of $\pm 8 \mathrm{~g}$ and a sampling rate of $64 \mathrm{~Hz}$. Reliability and validity of the device has been proven by Anastasopoulou et al. (2014), using indirect calorimetry as a reference measure for activity energy expenditure. As recommended by Ekblom Nyberg, Ekblom Bak, Ekelund and Marcus (2012), the accelerometers were attached to the child's non-dominant wrist, and based on body acceleration data, step counts per minute were used as main outcome variable.

Enjoyment of the activity was measured by the German short version of the Physical Activity Enjoyment Scale (PACES; Motl et al., 2001). The PACES has been translated into German and validated by Jekauc, Voelkle, Wagner, Mewes, and Woll (2013), proving to be a reliable and valid test for German-speaking children and adolescents. The short version (Dishman et al., 2005) only consists of the 7 negative items from the original scale, which are rated on a 5-point Likert scale ranging from 1 (strongly disagree) to 5 (strongly agree). Thus, low scores indicate high enjoyment of the activity. In the current study, internal consistency was acceptable with a Cronbach's alpha coefficient of 0.85 .

Cognitive exertion was measured with an adapted version of the SelfAssessment Manikin (SAM; Bradley \& Lang, 1994). The SAM is a widely used non-verbal pictorial assessment technique to measure an individual's affective reactions to a variety of stimuli. Acceptable reliability and validity has been demonstrated in a sample of 7-11 year olds being able to make dimensional ratings of pleasure and arousal in similar ways to adults (McManis, Bradley, Berg, Cuthbert, \& Lang, 2001). As in the original SAM, the rating scale ranged from 1 (low) to 9 (high) on which the children had to rate their perceived cognitive exertion answering the question: "How exhausting was the previous activity for your brain?". Despite not being a validated instrument, its usability to rate cognitive effort of different activities has been shown in children and adolescent samples (Benzing, Chang, \& Schmidt, 2018; Benzing et al., 2016; Egger et al., 2018).

\subsection{Experimental measures}

To test children's memory performance, an individual paper-andpencil cued recall test was used. In this test, all 20 exotic animal names were displayed in German and the children had to write down the French word. There were no time constraints and depending on the ability of the child, the test took between 5 and $15 \mathrm{~min}$. For each correctly recalled word, children received 1 point, with a minimum score of 0 and a maximum of 20 . The recalled words were also considered correct when minor spelling errors or singular-plural substitutions had occurred.

To assess children's attention, the d2- $\mathrm{R}$ test of attention (Brickenkamp, Schmidt-Atzert, \& Liepmann, 2010), which is the revised version of the $\mathrm{d} 2$ test of attention (Brickenkamp \& Zillmer, 1998), was used. The d2-R is a paper-and-pencil letter-cancellation test, consisting of 14 lines of 57 randomly mixed "p"s and "d"s, with one to four single quotation marks either above and/or below each letter. With $20 \mathrm{~s}$ allowed for each line, respondents are asked to strike out only the letter "d" with two dashes and to ignore all other distractors. After $20 \mathrm{~s}$, the experimenter gives an acoustic signal, which tells the participants to move to the next line. The entire test duration is $4 \mathrm{~min}$ and $40 \mathrm{~s}$. With no time constraints in the d2-R, virtually all subjects would solve all items correctly. However, the instruction to work as quickly and as accurately as possible leads to two types of errors: (1) omission errors, i.e. letters are omitted which should have been crossed out, and (2) commission errors, i.e. letters have been struck through that should have been left. The main outcome variable representing children's focused attention is the number of correct responses minus commission errors. The resulting raw scores were transformed to scaled scores (Brickenkamp et al., 2010). High scores indicate high attention. Split-half reliability for the age-group of 9-10-year-olds $(r=0.77-0.88)$ and test-retest reliability with a time interval of 4 months $(r=0.73-0.88)$ have both been shown to be acceptable (Brickenkamp et al., 2010).

\subsection{Statistical analyses}

To account for the hierarchical data structure, due to the children being clustered within classes, multilevel analyses were conducted (using the mixed models module of the Statistical Package for Social Sciences; SPSS 24.0). A two-level structure was applied, with children $(n=104)$ at the first level, and class $(n=6)$ at the second level. To test whether the full model fitted the data significantly better than the model in which only the intercepts were included, a $\chi^{2}$ difference test was used with -2 Log Likelihood as the information criterion. However, since convergence problems occurred (Tabachnick \& Fidell, 2013) in trying to set up multi-level models, in the preliminary analyses, i.e. to analyze the manipulation check and control variables, analyses of variance (ANOVAs) were used. When the overall ANOVA proved significant, Bonferroni-corrected post-hoc comparisons were used to determine the specific differences between the three groups. In the main analyses, multilevel analyses were conducted to test the impact of the three conditions on children's memory and attention performance, respectively. When the main fixed effect was significant, Bonferronicorrected post-hoc comparisons were used to determine the specific differences between the three groups. The level of significance was set at $p<.05$ for all analyses. Partial eta square $\left(\eta_{\mathrm{p}}{ }^{2}\right)$ and Cohen's $d$ were reported and interpreted by means of Cohen's (1988) definition of small, medium, and large effects (Partial eta square $=0.01,0.06,0.14$; Cohen's $d=0.20,0.50,0.80$ ).

\section{Results}

\subsection{Preliminary analyses}

To test whether the children in the two physically active conditions were actually more physically active than those in the sedentary condition, an ANOVA was conducted for their step counts per minute. Results showed that there was a significant effect of condition on counts per minute, $F(2,101)=156.95, p<.0005, \eta_{\mathrm{p}}{ }^{2}=0.757$, with post hoc comparisons revealing both the embodied learning, $p<.0005$, $d=4.71$, and the physical activity condition, $p<.0005, d=3.81$, being more physically exerting than the sedentary condition (Table 1 ). There was no difference between the two physically active conditions, $p=.145$.

The enjoyment varied significantly across conditions, $F(2$, 101) $=5.69, p=.005, \eta_{\mathrm{p}}{ }^{2}=0.101$, with both the embodied learning, $p=.017, d=0.52$, and the physical activity, $p=.002, d=0.86$, condition being more pleasant than the sedentary condition. There was no difference between the two physically active conditions, $p=.437$ (Table 1).

Interestingly, the perceived cognitive exertion also differed between the three conditions, $F(2,101)=3.77, p=.026, \eta_{\mathrm{p}}{ }^{2}=0.070$, with the control condition being experienced as being more cognitively exerting than the physical activity condition, $p=.023, d=0.74$, but not than the embodied learning condition, $p=.287$. The two physically active conditions did not differ in their amount of cognitive exertion induced, $p=.930$ (Table 1$)$.

\subsection{Main analyses}

To test the main hypotheses of the study, the three conditions were compared regarding their memory performance in the cued recall test and their attention performance in the $\mathrm{d} 2-\mathrm{R}$, respectively. Parameter estimates and statistics are presented in Table 2. A $\chi^{2}$ difference test 
Table 1

Means (and standard deviations) for the background, the manipulation check and the dependent variables in the three experimental conditions.

\begin{tabular}{|c|c|c|c|}
\hline & Embodied learning $(n=34)$ & Physical activity $(n=37)$ & Control $(n=33)$ \\
\hline \multicolumn{4}{|l|}{ Sample characteristics } \\
\hline Age (years) & $8.92(0.67)$ & $9.16(0.64)$ & $9.03(0.77)$ \\
\hline Height $(\mathrm{cm})$ & $141.23(6.41)$ & $139.24(6.83)$ & $137.70(6.10)$ \\
\hline Weight (kg) & $35.71(6.79)$ & $33.36(6.86)$ & $33.77(7.80)$ \\
\hline BMI $\left(\mathrm{kg} \cdot \mathrm{m}^{-2}\right)$ & $17.81(2.59)$ & $17.05(2.25)$ & $17.67(3.03)$ \\
\hline Gender distribution (male/female) & $15 / 19$ & $20 / 17$ & $19 / 14$ \\
\hline Socioeconomic status (0-9) & $6.12(1.82)$ & $6.41(1.54)$ & $6.00(2.03)$ \\
\hline \multicolumn{4}{|l|}{ Manipulation check and control variables } \\
\hline Physical activity (steps/min)* & $38.41(10.92)^{\mathrm{c}}$ & $33.93(11.68)^{\mathrm{c}}$ & $1.08(2.10)^{\mathrm{a}, \mathrm{b}}$ \\
\hline Enjoyment $(1-5)^{*}$ & $1.48(0.73)^{\mathrm{c}}$ & $1.36(0.47)^{\mathrm{c}}$ & $1.84(0.64)^{\mathrm{a}, \mathrm{b}}$ \\
\hline Cognitive exertion (1-9)* & $4.01(2.27)$ & $3.55(1.73)^{\mathrm{c}}$ & $4.79(1.60)^{\mathrm{b}}$ \\
\hline \multicolumn{4}{|l|}{ Experimental measures } \\
\hline Memory performance* & $4.62(2.47)^{\mathrm{c}}$ & $3.69(3.48)$ & $2.27(1.63)^{\mathrm{a}}$ \\
\hline Attention performance (pre) & $97.03(11.27)$ & $97.68(7.80)$ & $94.82(12.66)$ \\
\hline Attention performance (post) & $107.17(12.39)$ & $112.49(10.34)$ & $113.83(11.76)$ \\
\hline
\end{tabular}

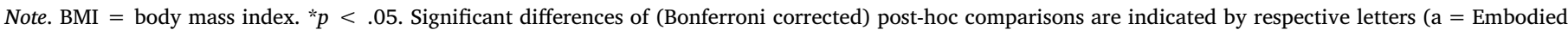
learning; $\mathrm{b}=$ Physical activity; $\mathrm{c}=\mathrm{Control}$ ). In enjoyment ratings, lower scores indicate higher enjoyment.

revealed that the full model (including the class as second-level factor) fitted the data significantly better than the intercepts-only model for both memory, $\chi^{2}(1, N=104)=496.60-489.51=7.09, p<.05$, and attention performance, $\chi^{2}(1, N=104)=734.00-697.92=36.08$, $p<.05$. Since correlational analyses showed that age (as the only one of all measured variables: $r s<0.075, p s>$.447) was significantly correlated with children's memory, $r=0.200, p=.041$, and attention performance, $r=0.235, p=.017$, it was included as the first covariate in the linear mixed models. To disentangle the effects of condition and physical activity, the objectively measured physical activity was included as a second covariate.

The linear mixed model controlling for age and step counts showed that there was a significant difference between the conditions in children's memory performance, $F(2,104.00)=8.34, p<.0005$, with post hoc comparisons revealing both the embodied learning, $p<.0005$, $d=1.12$, and the physical activity condition, $p=.002, d=0.51$, as being more effective in teaching children new words than the control condition (see Fig. 1a). Children's memory performance between the embodied learning and physical activity condition did not differ, $p=.257, d=0.31$. Whereas objectively measured physical activity had a significant effect on children's memory performance, $F(1$, $104.00)=6.37, p=.013$, children's age did not, $F(1,104.00)=3.48$, $p=.065$.

With respect to children's focused attention immediately after the learning session, the pattern of results contradicts our main study hypothesis (see Fig. 1b). Linear mixed models, controlling for age, step counts, and pretest measures of attention, showed that the three conditions did not differ in their attention, $F(2,8.02)=0.66, p=.545$. Neither children's age, $F(1,103.71)<0.01, p=.995$, nor their objectively measured physical activity, $F(1,103.49)=0.65, p=.422$, had a significant effect on children's attention. Not surprisingly, the pretest measure of attention significantly predicted the posttest measure of attention, $F(1,98.72)=143.58, p<.0005$.

\section{Discussion}

The aim of the present study was to investigate the effects of two specifically designed physical activity interventions on primary school

Table 2

Results of the two multilevel models with experimental condition as the independent variable and memory and attention as dependent variables.

\begin{tabular}{|c|c|c|c|c|c|c|c|}
\hline \multicolumn{8}{|c|}{ Random Effects } \\
\hline Level & Effect & Parameter Estimate & Standard Error & Wald $Z$ & $p$ & Lower & Upper \\
\hline \multicolumn{8}{|l|}{ Memory } \\
\hline Class & Intercept & 6.29 & 0.87 & 7.21 & $<.0005$ & 4.249 & 8.249 \\
\hline \multicolumn{8}{|l|}{ Attention } \\
\hline \multirow[t]{2}{*}{ Effect } & \multirow[t]{2}{*}{ Parameter Estimate } & \multirow[t]{2}{*}{ Standard Error } & \multirow[t]{2}{*}{ Approx df } & \multirow[t]{2}{*}{$t$ ratio } & \multirow[t]{2}{*}{$p$} & \multicolumn{2}{|c|}{ 95\% C.I. } \\
\hline & & & & & & Lower & Upper \\
\hline \multicolumn{8}{|l|}{ Memory } \\
\hline Embodied learning & 0 & 0 & . & . & . & & \\
\hline Physical activity & -1.067 & 0.615 & 104.00 & -1.73 & .086 & -2.287 & 0.153 \\
\hline
\end{tabular}

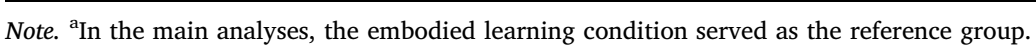


(a)

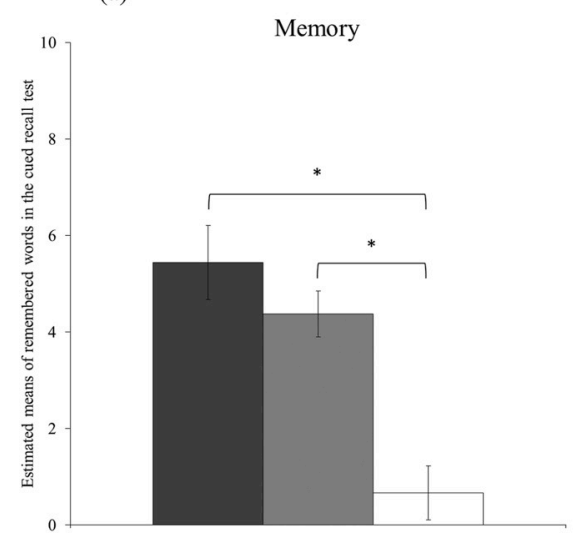

(b)

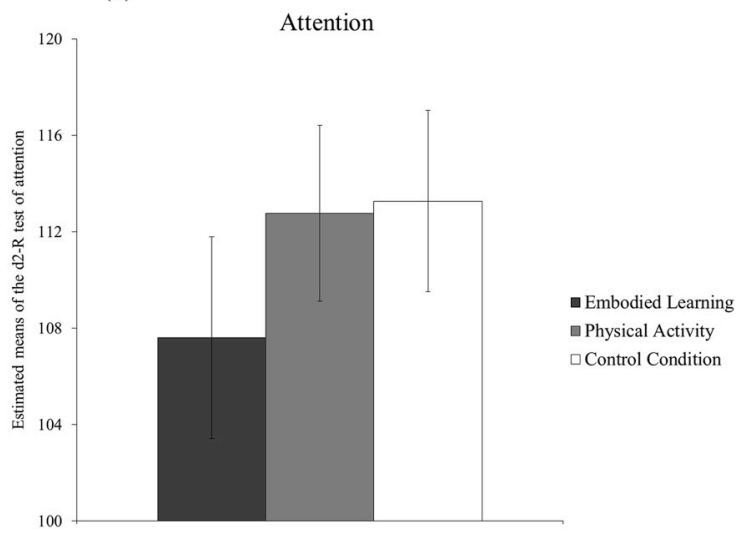

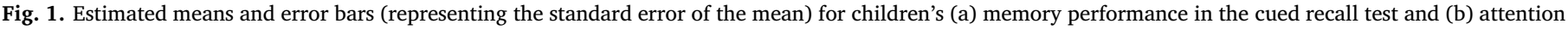
performance in the post test of the d2-R test of attention in the three experimental conditions. ${ }^{*} p<.05$.

children's foreign language vocabulary learning and attentional performance. Whereas the embodied learning condition consisted of taskrelated physical activities, the physical activity condition comprised of activities of the same intensity, which were, however, not related to the French words to be learnt. In the preliminary analyses, manipulation checks revealed that children of both the embodied learning and the physical activity condition were, not surprisingly, more physically active than their counterparts in the control condition. These results are in line with previous research showing embodied learning interventions (Mavilidi et al., 2015; Mavilidi, Okely, Chandler, Domazet, \& Paas, 2018; Mavilidi, Okely, Chandler, \& Paas, 2016, 2017) and physically active lessons (e.g., Kibbe et al., 2011; Riley et al., 2016) can increase school children's daily physical activity.

Children of both the embodied learning and the physical activity condition enjoyed the lessons more than children in the sedentary condition. This finding reflects what has been found previously in recent studies comparing embodied learning interventions (Mavilidi et al., 2016, 2017, 2018) or integrated physical activity lessons (Mullender-Wijnsma et al., 2016; Riley et al., 2016; Vazou \& SmileyOyen, 2014) to traditional sedentary teaching classes, with the result of higher values recorded in children's positive affective reactions. Positively influencing children's enjoyment though classroom-based physical activity is relevant for cognition, since changes in positive affect have been found to mediate the relationship between cognitive engaging activities and children's attentional performance (Schmidt et al., 2016), being interpreted as additional support of mood being a facilitator for cognitive processing (Forgas \& Eich, 2012; Isen, 2008). Thus, in future research, the affective outcomes of specific physical activities should be studied in more detail, to explore their role in enhancing children's cognitive performance by means of acute or chronic bouts of classroom-based physical activity.

\subsection{Attention}

Based on previous literature regarding the physiological effects of acute bouts of physical activity on children's attentional performance (Budde et al., 2008; Gallotta et al., 2015, 2012; Hill et al., 2010; Palmer et al., 2013; Schmidt et al., 2016; van den Berg et al., 2016), we hypothesized that children of both physical activity conditions would show better attentional performance immediately after a learning session than children in the control condition. However, the results of the main analyses showed that children's attention did not significantly differ between the three different conditions. These results contrast with the physiological mechanisms discussed in previous studies investigating the effects of acute physical activity on school children's cognition. Although such studies have focused on different physiological parameters, such as cerebral blood flow (Timinkul et al., 2008), brain-derived neurotrophic factor (Ferris et al., 2007; Winter et al., 2007), glucocorticoids (Blair et al., 2005) or catecholamines (Winter et al., 2007), the general assumption is that physiological adaptations lead to altered psychological states, such as increased arousal. This increased arousal should provide a larger pool of available attentional resources, thus facilitating performance in cognitively effortful tasks (Audiffren et al., 2009).

In the current study, however, the children assigned to the two physically active conditions did not outperform those assigned to the control condition. This could be due to the intensity of the chosen physical activities, as the objectively measured physical activity level of both physically active conditions was rather low, not reaching the threshold for light physical activity (Freedson, Pober, \& Janz, 2005; Trost, Loprinzi, Moore, \& Pfeiffer, 2011). Considering that these physiological changes are shown to be highly exercise intensity dependent (Blair et al., 2005; Ferris et al., 2007; Winter et al., 2007), and that a dose-response relationship between physical activity intensity and cognitive performance has been repeatedly reported (Chang, Etnier, \& Barella, 2009; Kamijo et al., 2004; McMorris \& Graydon, 1997), our two physically active conditions may not have reached a sufficient intensity to evoke these changes. Future studies should design and compare specific physical activities at different intensity levels to test this assumption.

Besides trying to elucidate the lacking effects on children's attention by analyzing the quantitative characteristics of the experimental conditions, e.g. physical activity intensity, it might also be valuable to examine the qualitative characteristics (Pesce, 2012), e.g. examining explanations for the amount of cognitive load being induced by different cognitive and physical activities (Paas, Renkl, \& Sweller, 2003). Previous research has shown that task-relevant physical activities within the instruction can save cognitive resources to be used during learning (Ping \& Goldin-Meadow, 2010). This was shown for co-speech gestures, which are normally made without conscious attention. However, in the present study, a considerable amount of engagement, concentration, and attention was required from children to achieve the desired learning outcomes (Blumenfeld, Kempler, \& Krajcik, 2006). Children of both physically active conditions not only had to learn the French words, they also had to connect the words to either task-relevant or irrelevant movements. Connecting information deriving from two different sources might have resulted in a greater cognitive load in the embodied learning condition than in the physical activity condition, because, for example, hopping like a kangaroo is probably more cognitively challenging than simply running on the spot. This explanation seems to be partly supported by children's self-reported measures of cognitive exertion: children in the control condition reported that their level of cognitive exertion was significantly higher compared to children in the physical activity condition, but not compared to the 
embodied learning condition.

As another theoretical explanation, children's level of cognitive exertion can be linked to mental effort (Chen, Castro-Alonso, Paas, \& Sweller, 2018; Paas, Tuovinen, Van Merriënboer, \& Darabi, 2005). Hence, the multimodal information arising from the external learning environment of movements requires greater attention and concentration by children, resulting in a substantial depletion of their attentional resources, even if they were not aware of additional mental effort they invested. This assumption seems corroborated by the findings of Gallotta et al. (2012), reporting that children's performance in the $\mathrm{d} 2$ test of attention showed lower improvement when assigned to the condition that involved coordinative physical education lesson with mixed cognitive and physical exertion. Furthermore, Egger et al. (2018) found deteriorative effects on children's executive functions after applying 20 min of physically and cognitively challenging physical activity. The authors of both studies interpret their results referring to the inverted u-shaped function between arousal and cognitive performance (Yerkes \& Dodson, 1908). Considering this, it remains an endeavor for future studies to test if an inverted u-shaped function between cognitively challenging physical activity and cognitive performance exists. Systematically manipulating both the cognitive exertion component and the duration of the cognitively challenging physical activity while controlling for its intensity level will be indispensable.

\subsection{Learning}

Both the embodied learning and the physical activity condition yielded better memory performance than the sedentary control condition, underlining the importance of including physical activity in the learning of a new language. Although the difference in the number of remembered words between the embodied learning condition and the physical activity condition was not significant, the two conditions differ considerably in the produced effect. Whereas the physical activity condition yielded a medium effect $(d=0.51)$, the embodied learning scenario has led to a large effect $(d=1.12)$. Therefore, the current study replicated the results of the studies of Mavilidi et al. (2015) and Toumpaniari et al. (2015) by showing that embodied learning of a foreign language vocabulary is more effective and enjoyable than the traditional sedentary way of learning. The large effect found for taskrelevant physical activity on learning outcomes aligns with the embodied cognition and the cognitive load theory. The use of body movements during the learning process assists in transforming abstract information into concrete and tangible concepts (Hostetter \& Alibali, 2008; Macedonia, 2014). Especially during foreign language learning, when newly learned words were encoded with movements, the motor image created was linked with the underlying mental representation of these words (Macedonia, Müller, \& Friederici, 2011). Task-relevant movements can potentially create a richer trace in the long-term memory, and consequently enhance the process of memory retrieval, resulting in better recall (Madan \& Singhal, 2012).

The sensorimotor experiences in the embodied learning condition allowed incoming information to be processed simultaneously through different modal sub-systems (i.e., seeing, hearing and enacting the words). From the perspective of cognitive load theory, this way of information processing is associated with a relative expansion the available processing capacity, enrichment of the resulting cognitive schema, and consequently better learning performance (Paas \& Sweller, 2012; Risko \& Gilbert, 2016). In terms of measuring cognitive load, the extraneous cognitive load (i.e., disruptive information) should be reduced to allow working memory capacity to be devoted to intrinsic (i.e. taskrelated information) cognitive load (Sweller, 2010). In the present study, the relevance of the movements, which included sensorimotor information, could have led to the construction of higher-quality mental representations. Thus, external environmental influence which would be disruptive or redundant in other cases was converted into useful information, enhancing the learning process and deliberating the inherent intrinsic complexity of the task (Van Merriënboer \& Sweller, 2005). In that sense, a better allocation of the working memory resources was achieved, with children of the embodied learning condition displaying the highest learning gains. Future research should try to investigate the effects of embodied learning on the different types of cognitive load, for example by using rating scales that can differentiate between the different types of load (e.g., Leppink, Paas, Van der Vleuten, Van Gog, \& Van Merriënboer, 2013; Leppink, Paas, Van Gog, Van der Vleuten, \& Van Merriënboer, 2014).

To conclude, this study offers a unique contribution to the field by examining both acute and chronic effects of physical activity on schoolchildren's attention and learning respectively. Additionally, the interaction of interdisciplinary research provides new conceptual interpretations using the theoretical frameworks based on the embodied cognition and cognitive load theory.

\subsection{Limitations and future directions}

Firstly, the duration of the intervention was relatively short. Importantly, including follow-up assessments several weeks after the end of the intervention (Mavilidi et al., 2015, 2018) will allow to infer on whether any observed effects are maintained over time. Along with children's assessments on learning progress, incorporating additional measures of standardized academic achievement (Donnelly et al., 2017) would enforce the generalizability of the results.

Secondly, considering the contrast between the results on children's cued recall and attention scores, possibly a variety of motivational factors (such as perceived self-efficacy, novelty of the lesson, children's enjoyment) may have positively affected children's learning performance. These factors could have facilitated children's attentional resources during the lesson, and as a result led to enhanced learning performance (Davies, 1983), however, they were not sufficient to maintain children's attention levels at the end of the lesson. Thus, future research should consist of interventions with longer duration that assess children's attention before and after each single learning session.

Thirdly, children's attention capacity was operationalized by measuring only its focused attention component - with the help of the d2-R test of attention. This decision was based on the importance of focused attention for academic learning, and its predictive validity for school performance (Steinmayr et al., 2010). The decision was also made considering the vast literature showing that the $\mathrm{d} 2$ test of attention is a sensible test to detect changes in cognitive performance induced by school-based physical activity interventions (Budde et al., 2008; Gallotta et al., 2015, 2012; Hill et al., 2010; Palmer et al., 2013; Schmidt et al., 2016; van den Berg et al., 2016). Bearing in mind that the two physically active conditions, especially the embodied cognition condition, were composed of activities in which motor actions had to be performed while simultaneously processing incoming information, one could speculate that such tasks also involve divided attention. Therefore, it could be useful for future studies to apply a similar study design, using a divided instead of a focused attention test as primary outcome variable to measure cognitive performance.

Finally, children wore accelerometer only during one learning session. Previous studies have used accelerometers during only the instruction phase or learning sessions (Mavilidi et al., 2015, 2016, 2017, 2018). However, comparing children's physical activity levels across the school day by collecting data for one week during school time before the intervention, and also for one week when the intervention is running (Riley et al., 2016), would produce a more representative sample of children's physical activity levels.

\section{Conclusions}

Overall, the results of this study reveal some insightful practical implications for practitioners and stake holders: Physical activity during learning is recommended to receive a prominent place within 
the traditional sedentary curriculum. Academic content is not compromised, instead it is enhanced and empowered as children learn better and more profoundly using this physically active approach. Concomitantly, children seem to enjoy physically active learning more than the traditional sedentary type of learning, thus their motivation to participate in learning might be higher. Additionally, embodied learning in the form of task-relevant movements seems to produce even greater effects than infusing simple task-unrelated physical activities in the curriculum. However, the results also suggest that a task-unrelated physical activity learning scenario, in contrast to one including taskrelevant physical activities, is perceived as being less cognitively demanding than the sedentary way of learning. Although embodied learning has produced higher learning gains than physically active learning, it might be advisable not to overlap such learning sessions with other cognitive activities, such as exams or complex and difficult assignments, to prevent children from becoming overloaded with cognitive demand.

\section{Acknowledgements}

We would like to thank the participating teachers and students and we also gratefully acknowledge the help of the MSc students involved in the data collection. This research was supported by the Swiss National Science Foundation (SNSF; grant number: IZSEZ0_178014).

\section{References}

Álvarez-Bueno, C., Pesce, C., Cavero-Redondo, I., Sánchez-López, M., Martínez-Hortelano, J. A., \& Martínez-Vizcaíno, V. (2017). The effect of physical activity interventions on children's cognition and metacognition: A systematic review and meta-analysis. Journal of the American Academy of Child \& Adolescent Psychiatry, 56(9), 729-738. https://doi.org/10.1016/j.jaac.2017.06.012.

Anastasopoulou, P., Tubic, M., Schmidt, S., Neumann, R., Woll, A., \& Härtel, S. (2014) Validation and comparison of two methods to assess human energy expenditure during free-living activities. PLoS One, 9(2), e90606. https://doi.org/10.1371/ journal.pone.0090606.

Audiffren, M., Tomporowski, P. D., \& Zagrodnik, J. (2009). Acute aerobic exercise and information processing: Modulation of executive control in a random number generation task. Acta Psychologica, 132(1), 85-95. https://doi.org/10.1016/j.actpsy. 2009.06.008.

Barsalou, L. W. (2008). Grounded cognition. Annual Review of Psychology, 59, 617-645. https://doi.org/10.1146/annurev.psych.59.103006.093639.

Bartholomew, J. B., Golaszewski, N. M., Jowers, E., Korinek, E., Roberts, G., Fall, A., \& Vaughn, S. (2018). Active learning improves on-task behaviors in 4th grade children. Preventive Medicine, 111, 49-54. https://doi.org/10.1016/j.ypmed.2018.02.023.

Bartholomew, J. B., \& Jowers, E. M. (2011). Physically active academic lessons in elementary children. Preventive Medicine, 52, 51-54. https://doi.org/10.1016/j.ypmed. 2011.01.017.

Beck, M. M., Lind, R. R., Geertsen, S. S., Ritz, C., Lundbye-Jensen, J., \& Wienecke, J. (2016). Motor-enriched learning activities can improve mathematical performance in preadolescent children. Frontiers in Human Neuroscience, 10, 645. https://doi.org/10. 3389/fnhum.2016.00645.

Benzing, V., Chang, Y.-K., \& Schmidt, M. (2018). Acute physical activity enhances executive functions in children with ADHD. Scientific Reports, 8(1), 12382. https://doi. org/10.1038/s41598-018-30067-8.

Benzing, V., Heinks, T., Eggenberger, N., \& Schmidt, M. (2016). Acute cognitively engaging exergame-based physical activity enhances executive functions in adolescents. PLoS One, 11(12), e0167501. https://doi.org/10.1371/journal.pone.0167501.

van den Berg, V., Saliasi, E., de Groot, Renate, H. M., Jolles, J., Chinapaw, M. J. M., \& Singh, A. S. (2016). Physical activity in the school setting: Cognitive performance is not affected by three different types of acute exercise. Frontiers in Psychology, 7, 723. https://doi.org/10.3389/fpsyg.2016.00723.

Best, J. R. (2010). Effects of physical activity on children's executive function: Contributions of experimental research on aerobic exercise. Developmental Review, 30(4), 331-351. https://doi.org/10.1016/j.dr.2010.08.001.

Best, J. R. (2012). Exergaming immediately enhances children's executive function. Developmental Psychology, 48(5), 1501-1510. https://doi.org/10.1037/a0026648.

Blair, C., Granger, D., \& Peters Razza, R. (2005). Cortisol reactivity is positively related to executive function in preschool children attending head start. Child Development, 76(3), 554-567. https://doi.org/10.1111/j.1467-8624.2005.00863.x.

Blumenfeld, P. C., Kempler, T. M., \& Krajcik, J. S. (2006). Motivation and cognitive en gagement in learning environments. In R. K. Sawyer (Ed.). The Cambridge handbook of: The learning sciences (pp. 475-488). New York, NY: Cambridge University Press.

Boudreau, B., \& Poulin, C. (2009). An examination of the validity of the Family Affluence Scale II (FAS II) in a general adolescent population of Canada. Social Indicators Research, 94, 29-42. https://doi.org/10.1007/s11205-008-9334-4.

Bradley, M. M., \& Lang, P. J. (1994). Measuring emotion: The self-assessment manikin and the semantic differential. Journal of Behavior Therapy and Experimental Psychiatry, 25(1), 49-59. https://doi.org/10.1016/0005-7916(94)90063-9.

Brickenkamp, R., Schmidt-Atzert, L., \& Liepmann, D. (2010). Test d2-R - revision. Aufmerksamkeits- und konzentrationstest [test d2-R - revision: Attention and concentration test]. Göttingen: Hogrefe.

Brickenkamp, R., \& Zillmer, E. (1998). The d2 test of attention. Seattle, WA: Hogrefe \& Huber Publishers.

Budde, H., Voelcker-Rehage, C., Pietraßyk-Kendziorra, S., Ribeiro, P., Tidow, G., Pietrabyk-Kendziorra, S., \& Tidow, G. (2008). Acute coordinative exercise improves attentional performance in adolescents. Neuroscience Letters, 441(2), 219-223. https://doi.org/10.1016/j.neulet.2008.06.024.

Chandler, P., \& Tricot, A. (2015). Mind Your Body: The Essential role of body movements in children's learning. Educational Psychology Review, 27(3), 365-370. https://doi. org/10.1007/s10648-015-9333-3.

Chang, Y.-K., Etnier, J. L., \& Barella, L. A. (2009). Exploring the relationship between exercise-induced arousal and cognition using fractionated response time. Research Quarterly for Exercise \& Sport, 80(1), 78-86. https://doi.org/10.1080/02701367. 2009.10599532.

Chen, O., Castro-Alonso, J. C., Paas, F., \& Sweller, J. (2018). Extending cognitive load theory to incorporate working memory resource depletion: Evidence from the spacing effect. Educational Psychology Review, 30, 483-501. https://doi.org/10.1007/s10648017-9426-2.

Choi, H. H., Van Merriënboer, J. J. G., \& Paas, F. (2014). Effects of the physical environment on cognitive load and learning: Towards a new model of cognitive load. Educational Psychology Review, 26, 225-244. https://doi.org/10.1007/s10648-0149262-6.

Cohen, J. (1988). Statistical power analysis for the behavioral sciences (2nd ed.). Hillsdale, NJ: Lawrence Erlbaum Associates.

Cook, S. W., Mitchell, Z., \& Goldin-Meadow, S. (2008). Gesturing makes learning last. Cognition, 106(2), 1047-1058. https://doi.org/10.1016/j.cognition.2007.04.010.

Cook, S. W., Yip, T. K., \& Goldin-Meadow, S. (2012). Gestures, but not meaningless movements, lighten working memory load when explaining math. Language \& Cognitive Processes, 27(4), 594-610. https://doi.org/10.1080/01690965.2011. 567074.

Cox, M., Schofield, G., \& Kolt, G. S. (2010). Responsibility for children's physical activity: Parental, child, and teacher perspectives. Journal of Science and Medicine in Sport, 13 46-52. https://doi.org/10.1016/j.jsams.2009.02.006.

Davies, D. R. (1983). Attention, arousal and effort. In A. Gale, \& J. A. Edwards (Eds.) Physiological correlates of human behaviour. London: Academic Press.

Dishman, R. K., Motl, R. W., Sallis, J. F., Dunn, A. L., Birnbaum, A. S., Welk, G. J., ... Jobe, J. B. (2005). Self-management strategies mediate self-efficacy and physical activity. American Journal of Preventive Medicine, 29(1), 10-18. http://doi.org/10.1016/j amepre.2005.03.012.

Donnelly, J. E., Greene, J. L., Gibson, C. A., Smith, B. K., Washburn, R. A., Sullivan, D. K., ... Williams, S. L. (2009). Physical activity across the curriculum (PAAC): A randomized controlled trial to promote physical activity and diminish overweight and obesity in elementary school children. Preventive Medicine, 49(4), 336-341. https:// doi.org/10.1016/j.ypmed.2009.07.022.

Donnelly, J. E., Hillman, C. H., Castelli, D., Etnier, J. L., Lee, S., Tomporowski, P., ... Szabo-Reed, A. N. (2016). Physical activity, fitness, cognitive function, and academic achievement in children: A systematic review. Medicine \& Science in Sports \& Exercise, 48(6), 1223-1224. https://doi.org/10.1249/MSS.0000000000000966.

Donnelly, J. E., Hillman, C. H., Greene, J. L., Hansen, D. M., Gibson, C. A., Sullivan, D. K., ... Washburn, R. A. (2017). Physical activity and academic achievement across the curriculum: Results from a 3-year cluster-randomized trial. Preventive Medicine, 99, 140-145. https://doi.org/10.1016/j.ypmed.2017.02.006.

Egger, F., Conzelmann, A., \& Schmidt, M. (2018). The effect of acute cognitively engaging physical activity breaks on children's executive functions: Too much of a good thing? Psychology of Sport and Exercise, 36, 178-186. https://doi.org/10.1016/j.psychsport. 2018.02.014.

Ekblom, O., Nyberg, G., Ekblom Bak, E., Ekelund, U., \& Marcus, C. (2012). Validity and comparability of a wrist-worn accelerometer in children. Journal of Physical Activity and Health, 9(3), 389-393. https://doi.org/10.1123/jpah.9.3.389.

Erwin, H., Fedewa, A., Beighle, A., \& Ahn, S. (2012). A quantitative review of physical activity, health, and learning outcomes associated with classroom-based physical activity interventions. Journal of Applied School Psychology, 28(1), 14-36. https://doi. org/10.1080/15377903.2012.643755.

Etnier, J. L., Salazar, W., Landers, D. M., Petruzzello, S. J., Han, M., Nowell, P., ... Nowell, P. (1997). The influence of physical fitness and exercise upon cognitive functioning. A meta-analysis. Journal of Sport \& Exercise Psychology, 19(3), 249-277. https://doi. org/10.1123/jsep.19.3.249.

Faul, F., Erdfelder, E., Lang, A.-G., \& Buchner, A. (2007). G*Power 3: A flexible statistica power analysis program for the social, behavioral, and biomedical sciences. Behavior Research Methods, 39(2), 175-191. https://doi.org/10.3758/BF03193146.

Ferris, L. T., Williams, J. S., \& Shen, C.-L. (2007). The effect of acute exercise on serum brain-derived neurotrophic factor levels and cognitive function. Medicine \& Science in Sports \& Exercise, 39(4), 728-734. https://doi.org/10.1249/mss.0b013e31802f04c7.

Forgas, J. P., \& Eich, E. (2012). Affective influences on cognition: Mood congruence, mood dependence, and mood effects on processing strategies. In A. F. Healy, R. W. Proctor, \& I. B. Weiner (Eds.). Handbook of psychology: Volume 4 experimental psychology (pp. 61-82). (2nd ed.). Hoboken, NJ: John Wiley; Wiley.

Freedson, P., Pober, D., \& Janz, K. F. (2005). Calibration of accelerometer output for children. Medicine \& Science in Sports \& Exercise, 37(Suppl. ment), S523-S530. https://doi.org/10.1249/01.mss.0000185658.28284.ba.

Gallotta, M. C., Emerenziani, G. P., Franciosi, E., Meucci, M., Guidetti, L., \& Baldari, C. (2015). Acute physical activity and delayed attention in primary school students. 
Scandinavian Journal of Medicine \& Science in Sports, 25(3), e331-e338. https://doi. org/10.1111/sms.12310.

Gallotta, M. C., Guidetti, L., Franciosi, E., Emerenziani, G. P., Bonavolonta, V., \& Baldari, C. (2012). Effects of varying type of exertion on children's attention capacity. Medicine \& Science in Sports \& Exercise, 44(3), 550-555. https://doi.org/10.1249/ MSS.0b013e3182305552.

Glenberg, A. M., Witt, J. K., \& Metcalfe, J. (2013). From the revolution to embodiment: 25 years of cognitive psychology. Perspectives on Psychological Science, 8(5), 573-585. https://doi.org/10.1177/1745691613498098.

Goldin-Meadow, S., \& Beilock, S. L. (2010). Action's influence on thought: The case of gesture. Perspectives on Psychological Science, 5(6), 664-674. https://doi.org/10. $1177 / 1745691610388764$

Goldin-Meadow, S., Nusbaum, H., Kelly, S. D., \& Wagner, S. (2001). Explaining math: Gesturing lightens the load. Psychological Science, 12(6), 516-522. https://doi.org/ 10.1111/1467-9280.00395.

Goldin-Meadow, S., \& Wagner, S. M. (2005). How our hands help us learn. Trends in Cognitive Sciences, 9(5), 234-241. https://doi.org/10.1016/j.tics.2005.03.006.

Grieco, L. A., Jowers, E. M., \& Bartholomew, J. B. (2009). Physically active academic lessons and time on task: The moderating effect of body mass index. Medicine \& Science in Sports \& Exercise, 41(10), 1921-1926. https://doi.org/10.1249/MSS. 0b013e3181a61495.

Hallal, P. C., Andersen, L. B., Bull, F. C., Guthold, R., Haskell, W., \& Ekelund, U. (2012). Global physical activity levels: Surveillance progress, pitfalls, and prospects. The Lancet, 380(9838), 247-257. https://doi.org/10.1016/S0140-6736(12)60646-1.

Hill, L., Williams, J. H. G., Aucott, L., Milne, J., Thomson, J., Greig, J., ... Mon-Williams, M. (2010). Exercising attention within the classroom. Developmental Medicine and Child Neurology, 52(10), 929-934. https://doi.org/10.1111/j.1469-8749.2010. 03661.x.

Hostetter, A. B., \& Alibali, M. W. (2008). Visible embodiment: Gestures as simulated action. Psychonomic Bulletin \& Review, 15(3), 495-514. https://doi.org/10.3758/PBR. 15.3.495.

Howie, E. K., Beets, M. W., \& Pate, R. R. (2014). Acute classroom exercise breaks improve on-task behavior in 4th and 5th grade students: A dose-response. Mental Health and Physical Activity, 7(2), 65-71. https://doi.org/10.1016/j.mhpa.2014.05.002.

Howie, E. K., Schatz, J., \& Pate, R. R. (2015). Acute effects of classroom exercise breaks on executive function and math performance: A dose-response study. Research Quarterly for Exercise \& Sport, 86(3), 217-224. https://doi.org/10.1080/02701367.2015. 1039892.

Isen, A. M. (2008). Some ways in which positive affect influences decision making and problem solving. In M. Lewis, J. M. Haviland-Jones, \& L. F. Barrett (Eds.). Handbook of emotions (pp. 548-573). (3rd ed.). New York: Guilford Press.

Jäger, K., Schmidt, M., Conzelmann, A., \& Roebers, C. M. (2014). Cognitive and physiological effects of an acute physical activity intervention in elementary school children. Frontiers in Psychology, 5, 71. https://doi.org/10.3389/fpsyg.2014.01473.

Jäger, K., Schmidt, M., Conzelmann, A., \& Roebers, C. M. (2015). The effects of qualitatively different acute physical activity interventions in real-world settings on executive functions in preadolescent children. Mental Health and Physical Activity, 9, 1-9. https://doi.org/10.1016/j.mhpa.2015.05.002.

Jekauc, D., Voelkle, M., Wagner, M. O., Mewes, N., \& Woll, A. (2013). Reliability, validity, and measurement invariance of the German version of the physical activity enjoyment scale. Journal of Pediatric Psychology, 38(1), 104-115. http://doi.org/10. 1093/jpepsy/jss088.

Kamijo, K., Nishihira, Y., Hatta, A., Kaneda, T., Kida, T., Higashiura, T., \& Kuroiwa, K. (2004). Changes in arousal level by differential exercise intensity. Clinical Neurophysiology, 115(12), 2693-2698. https://doi.org/10.1016/j.clinph.2004.06. 016.

Khan, N. A., \& Hillman, C. H. (2014). The relation of childhood physical activity and aerobic fitness to brain function and cognition: A review. Pediatric Exercise Science, 26(2), 138-146. https://doi.org/10.1123/pes.2013-0125.

Kibbe, D. L., Hackett, J., Hurley, M., McFarland, A., Schubert, K. G., Schultz, A., \& Harris, S. (2011). Ten Years of TAKE 10!: Integrating physical activity with academic concepts in elementary school classrooms. Preventive Medicine, 52(Suppl. 1), 43-50. https://doi.org/10.1016/j.ypmed.2011.01.025.

Kubesch, S., Walk, L., Spitzer, M., Kammer, T., Lainburg, A., Heim, R., \& Hille, K. (2009). A 30-minute physical education program improves students' executive attention. Mind Brain and Education, 3(4), 235-242. https://doi.org/10.1111/j.1751-228X. 2009.01076.x.

Leppink, J., Paas, F., Van Gog, T., Van der Vleuten, C. P. M., \& Van Merriënboer, J. J. G. (2014). Effects of pairs of problems and examples on task performance and different types of cognitive load. Learning and Instruction, 30, 32-42. https://doi.org/10.1016/ j.learninstruc.2013.12.001

Leppink, J., Paas, F., Van der Vleuten, C. P. M., Van Gog, T., \& Van Merriënboer, J. J. G. (2013). Development of an instrument for measuring different types of cognitive load. Behavior Research Methods, 45, 1058-1072. https://doi.org/10.3758/s13428013-0334-1.

Lindgren, R., Tscholl, M., Wang, S., \& Johnson, E. (2016). Enhancing learning and engagement through embodied interaction within a mixed reality simulation. Computers \& Education, 95, 174-187. https://doi.org/10.1016/j.compedu.2016.01.001.

Little, R. J. A., \& Rubin, D. B. (2002). Statistical analysis with missing data (2nd ed.). New York, NY: John Wiley \& Sons.

Lubans, D., Richards, J., Hillman, C., Faulkner, G., Beauchamp, M., Nilsson, M., ... Biddle, S. (2016). Physical activity for cognitive and mental health in youth: A systematic review of mechanisms. Pediatrics, 138(3), e20161642. https://doi.org/10.1542/peds. 2016-1642.

Macedonia, M. (2014). Bringing back the body into the mind: Gestures enhance word learning in foreign language. Frontiers in Psychology, 5, 1467. https://doi.org/10. 3389/fpsyg.2014.01467.

Macedonia, M., Müller, K., \& Friederici, A. D. (2011). The impact of iconic gestures on foreign language word learning and its neural substrate. Human Brain Mapping, 32(6), 982-998. https://doi.org/10.1002/hbm.21084.

Madan, C. R., \& Singhal, A. (2012). Encoding the world around us: Motor-related processing influences verbal memory. Consciousness and Cognition, 21(3), 1563-1570. https://doi.org/10.1016/j.concog.2012.07.006.

Mahar, M. T., Murphy, S. K., Rowe, D. A., Golden, J., Shields, A. T., \& Raedeke, T. D. (2006). Effects of a classroom-based program on physical activity and on-task behavior. Medicine \& Science in Sports \& Exercise, 38(12), 2086-2094. https://doi.org/ 10.1249/01.mss.0000235359.16685.a3.

Ma, J. K., Le Mare, L., \& Gurd, B. J. (2014). Classroom-based high-intensity interval activity improves off-task behaviour in primary school students. Applied Physiology Nutrition and Metabolism, 39(12), 1332-1337. https://doi.org/10.1139/apnm-20140125 .

Mavilidi, M. F., Okely, A. D., Chandler, P., Cliff, D. P., \& Paas, F. (2015). Effects of integrated physical exercises and gestures on preschool children's foreign language vocabulary learning. Educational Psychology Review, 27(3), 413-426. https://doi.org/ 10.1007/s10648-015-9337-z.

Mavilidi, M. F., Okely, A., Chandler, P., Domazet, S. L., \& Paas, F. (2018a). Immediate and delayed effects of integrating physical activity into preschool children's learning of numeracy skills. Journal of Experimental Child Psychology, 166, 502-519. https://doi. org/10.1016/j.jecp.2017.09.009.

Mavilidi, M. F., Okely, A. D., Chandler, P., \& Paas, F. (2016). Infusing physical activities into the classroom: Effects on preschool children's geography learning. Mind, Brain, and Education, 10(4), 256-263. https://doi.org/10.1111/mbe.12131.

Mavilidi, M. F., Okely, A. D., Chandler, P., \& Paas, F. (2017). Effects of integrating physical activities into a science lesson on preschool children's learning and enjoyment. Applied Cognitive Psychology, 31(3), 281-290. https://doi.org/10.1002/acp. 3325 .

Mavilidi, M. F., Ruiter, M., Schmidt, M., Okely, A. D., Loyens, S., Chandler, P., \& Paas, F. (2018b). A narrative review of school-based physical activity for enhancing cognition and learning: The importance of relevancy and integration. Frontiers in Psychology, 9, 2079. https://doi.org/10.3389/fpsyg.2018.02079.

McManis, M. H., Bradley, M. M., Berg, K.,W., Cuthbert, B. N., \& Lang, P.,J. (2001). Emotional reactions in children: Verbal, physiological, and behavioral responses to affective pictures. Psychophysiology, 38, 222-231. https://doi.org/10.1111/14698986.3820222.

McMorris, T., \& Graydon, J. (1997). The effect of exercise on cognitive performance in soccer-specific tests. Journal of Sports Sciences, 15(5), 459-468. https://doi.org/10. $1080 / 026404197367092$

Motl, R. W., Dishman, R. K., Saunders, R., Dowda, M., Felton, G., \& Pate, R. R. (2001). Measuring enjoyment of physical activity in adolescent girls. American Journal of Preventive Medicine, 21(2), 110-117. https://doi.org/10.1016/S0749-3797(01) 00326-9.

Mullender-Wijnsma, M. J., Hartman, E., de Greeff, J. W., Doolaard, S., Bosker, R. J., \& Visscher, C. (2016). Physically active math and language lessons improve academic achievement: A cluster randomized controlled trial. Pediatrics, peds-2015. https://doi. org/10.1542/peds.2015-2743.

Naylor, P. J., \& McKay, H. A. (2009). Prevention in the first place: Schools a setting for action on physical inactivity. British Journal of Sports Medicine, 43(1), 10-13. https:// doi.org/10.1136/bjsm.2008.053447.

Naylor, P.-J., Nettlefold, L., Race, D., Hoy, C., Ashe, M. C., Wharf Higgins, J., \& McKay, H. A. (2015). Implementation of school based physical activity interventions: A systematic review. Preventive Medicine, 72, 95-115. https://doi.org/10.1016/j.ypmed. 2014.12.034.

Oberer, N., Gashaj, V., \& Roebers, C. M. (2018). Executive functions, visual-motor coordination, physical fitness and academic achievement: Longitudinal relations in typically developing children. Human Movement Science, 58, 69-79. https://doi.org/ 10.1016/j.humov.2018.01.003.

Paas, F., Renkl, A., \& Sweller, J. (2003). Cognitive load theory and instructional design Recent developments. Educational Psychologist, 38(1), 1-4. https://doi.org/10.1207/ S15326985EP3801_1.

Paas, F., \& Sweller, J. (2012). An evolutionary upgrade of cognitive load theory: Using the human motor system and collaboration to support the learning of complex cognitive tasks. Educational Psychology Review, 24(1), 27-45. https://doi.org/10.1007/s10648 011-9179-2.

Paas, F., Tuovinen, J. E., Van Merriënboer, J. J., \& Darabi, A. A. (2005). A motivational perspective on the relation between mental effort and performance: Optimizing learner involvement in instruction. Educational Technology Research \& Development 53(3), 25-34. https://doi.org/10.1007/BF02504795.

Palmer, K. K., Miller, M. W., \& Robinson, L. E. (2013). Acute exercise enhances preschoolers' ability to sustain attention. Journal of Sport \& Exercise Psychology, 35(4), 433-437. https://doi.org/10.1123/jsep.35.4.433.

Pesce, C. (2012). Shifting the focus from quantitative to qualitative exercise characteristics in exercise and cognition research. Journal of Sport \& Exercise Psychology, 34(6), 766-786. https://doi.org/10.1123/jsep.34.6.766.

Pesce, C., \& Ben-Soussan, T. D. (2016). "Cogito ergo sum" or "ambulo ergo sum"? New perspectives in developmental exercise and cognition research. In T. McMorris (Ed.) Exercise-cognition interaction: Neuroscience perspectives (pp. 251-282). London: Elsevier. https://doi.org/10.1016/B978-0-12-800778-5.00012-8.

Pesce, C., Crova, C., Cereatti, L., Casella, R., \& Bellucci, M. (2009). Physical activity and mental performance in preadolescents: Effects of acute exercise on free-recall memory. Mental Health and Physical Activity, 2(1), 16-22. https://doi.org/10.1016/j. mhpa.2009.02.001.

Ping, R., \& Goldin-Meadow, S. (2010). Gesturing saves cognitive resources when talking 
about nonpresent objects. Cognitive Science, 34(4), 602-619. https://doi.org/10. 1111/j.1551-6709.2010.01102.x.

Poitras, V. J., Gray, C. E., Borghese, M. M., Carson, V., Chaput, J.-P., Janssen, I., ... Tremblay, M. S. (2016). Systematic review of the relationships between objectively measured physical activity and health indicators in school-aged children and youth. Applied Physiology Nutrition and Metabolism, 41(6), 197-239. https://doi.org/10. 1139/apnm-2015-0663.

Posner, M. I., \& DiGirolamo, G. J. (1998). Executive attention: Conflict, target detection, and cognitive control. In R. Parasuraman (Ed.). The attentive brain (pp. 401-423). Cambridge, MA: MIT Press.

Riley, N., Lubans, D. R., Holmes, K., \& Morgan, P. J. (2016). Findings from the EASY Minds cluster randomized controlled trial: Evaluation of a physical activity integration program for mathematics in primary schools. Journal of Physical Activity and Health, 13(2), 198-206. https://doi.org/10.1123/jpah.2015-0046.

Risko, E. F., \& Gilbert, S. J. (2016). Cognitive offloading. Trends in Cognitive Sciences, 20(9), 676-688. https://doi.org/10.1016/j.tics.2016.07.002.

Schmidt, M., Benzing, V., \& Kamer, M. (2016). Classroom-based physical activity breaks and children's attention: Cognitive engagement works!. Frontiers in Psychology, 7, 1474. https://doi.org/10.3389/fpsyg.2016.01474.

Schmidt, M., Egger, F., Benzing, V., Jäger, K., Conzelmann, A., Roebers, C. M., \& Pesce, C. (2017). Disentangling the relationship between children's motor ability, executive function and academic achievement. PLoS One, 12(8), e0182845. https://doi.org/10. 1371/journal.pone.0182845.

Shoval, E. (2011). Using mindful movement in cooperative learning while learning about angles. Instructional Science, 39(4), 453-466. https://doi.org/10.1007/s11251-0109137-2.

Steele, A., Karmiloff-Smith, A., Cornish, K., \& Scerif, G. (2012). The multiple subfunctions of attention: Differential developmental gateways to literacy and numeracy. Child Development, 83(6), 2028-2041. https://doi.org/10.1111/j.1467-8624.2012. 01809.x.

Steinmayr, R., Ziegler, M., \& Träuble, B. (2010). Do intelligence and sustained attention interact in predicting academic achievement? Learning and Individual Differences, 20(1), 14-18. https://doi.org/10.1016/j.lindif.2009.10.009.

Sweller, J. (2010). Element interactivity and intrinsic, extraneous and germane cognitive load. Educational Psychological Review, 22(2), 123-138. https://doi.org/10.1007/ s10648-010-9128-5.

Tabachnick, B. G., \& Fidell, L. S. (2013). Using multivariate statistics. Boston: Pearson.

Timinkul, A., Kato, M., Omori, T., Deocaris, C. C., Ito, A., Kizuka, T., ... Soya, H. (2008). Enhancing effect of cerebral blood volume by mild exercise in healthy young men: A near-infrared spectroscopy study. Neuroscience Research, 61(3), 242-248. https://doi. org/10.1016/j.neures.2008.03.012.
Tomporowski, P. D., McCullick, B., Pendleton, D. M., \& Pesce, C. (2015). Exercise and children's cognition: The role of exercise characteristics and a place for metacognition. Journal of Sport and Health Science, 4(1), 47-55. https://doi.org/10.1016/j.jshs. 2014.09.003.

Toumpaniari, K., Loyens, S., Mavilidi, M. F., \& Paas, F. (2015). Preschool children's foreign language vocabulary learning by embodying words through physical activity and gesturing. Educational Psychology Review, 27(3), 445-456. https://doi.org/10. 1007/s10648-015-9316-4.

Tremblay, M. S., Gray, C. E., Akinroye, K., Harrington, D. M., Katzmarzyk, P. T., Lambert, E. V., ... Tomkinson, G. (2014). Physical activity of children: A global matrix of grades comparing 15 countries. Journal of Physical Activity and Health, 11(S1), 113-125. https://doi.org/10.1123/jpah.2014-0177.

Trost, S. G., Loprinzi, P. D., Moore, R., \& Pfeiffer, K. A. (2011). Comparison of accelerometer cut points for predicting activity intensity in youth. Medicine \& Science in Sports \& Exercise, 43(7), 1360-1368. https://doi.org/10.1249/MSS. ob013e318206476e.

Van Merriënboer, J. J., \& Sweller, J. (2005). Cognitive load theory and complex learning: Recent developments and future directions. Educational Psychology Review, 17(2), 147-177. https://doi.org/10.1007/s10648-005-3951-0.

Vazou, S., Pesce, C., Lakes, K., \& Smiley-Oyen, A. (2016). More than one road leads to rome: A narrative review and meta-analysis of physical activity intervention effects on cognition in youth. International Journal of Sport and Exercise Psychology, 1-26. https://doi.org/10.1080/1612197X.2016.1223423.

Vazou, S., \& Smiley-Oyen, A. (2014). Moving and academic learning are not antagonists: Acute effects on executive function and enjoyment. Journal of Sport \& Exercise Psychology, 36(5), 474-485. https://doi.org/10.1123/jsep.2014-0035.

Watson, A., Timperio, A., Brown, H., Best, K., \& Hesketh, K. D. (2017). Effect of classroom-based physical activity interventions on academic and physical activity outcomes: A systematic review and meta-analysis. International Journal of Behavioral Nutrition and Physical Activity, 14(1), 114. https://doi.org/10.1186/s12966-0170569-9.

Webster, C. A., Russ, L., Vazou, S., Goh, T. L., \& Erwin, H. (2015). Integrating movement in academic classrooms: Understanding, applying and advancing the knowledge base. Obesity Reviews, 16(8), 691-701. https://doi.org/10.1111/obr.12285.

Winter, B., Breitenstein, C., Mooren, F. C., Voelker, K., Fobker, M., Lechtermann, A., ... Knecht, S. (2007). High impact running improves learning. Neurobiology of Learning and Memory, 87(4), 597-609. https://doi.org/10.1016/j.nlm.2006.11.003.

Yerkes, R. M., \& Dodson, J. D. (1908). The relation of strength of stimulus to rapidity of habit-formation. Journal of Comparative Neurology, 18(5), 459-482. https://doi.org/ 10.1002/cne.920180503. 